\title{
Role of Endoscopy in the Management of Boerhaave Syndrome
}

\author{
Juan Ignacio Tellechea ${ }^{1}$, Jean-Michel Gonzalez', Pablo Miranda-García ${ }^{1}$, Adrian Culetto ${ }^{1}$, Xavier Benoit D'Journo ${ }^{2}$, \\ Pascal Alexandre Thomas ${ }^{2}$ and Marc Barthet ${ }^{1}$ \\ Department of ${ }^{1}$ Gastroenterology, ${ }^{2}$ Thoracic Surgical, North Hospital, University of Mediterranean, Chemin des Bourrely, Marseille, France
}

Boerhaave syndrome (BS) is a spontaneous esophageal perforation which carries high mortality. Surgical treatment is well established, but the development of interventional endoscopy has proposed new therapies. We expose our experience in a Gastrointestinal and Endoscopy Unit. With a retrospective, observational, open-label, single center, consecutive case series. All patients diagnosed with BS who were managed in our center were included. Treated conservatively, endoscopically or surgically, according to their clinical condition and lesion presentation. Fourteen patients were included. Ten were treated with primary surgery. One conservatively. In total, 7/14 patients required an endoscopic treatment. All required metallic stents deployment, 3 cases over-the-scope-clips concomitantly and one case a novel technique an internal drain. 6/7 cases endoscopically treated achieved complete esophageal healing. In conclusion, endoscopy is an useful tool at all stages BS management: difficult diagnosis, primary treatment in selected patients and as salvage when surgery fails. With mortality rates and outcomes comparables to surgery. Clin Endosc 2018;51:186-191

Key Words: Esophageal perforation; Stents; Surgical instruments; Endoscopy; Minimally invasive surgical procedures

\section{INTRODUCTION}

Boerhaave syndrome (BS), a rare condition associated with high mortality, ${ }^{1}$ is defined as a spontaneous esophageal perforation of a normal esophagus unrelated to foreign bodies, previous instrumentation, surgery, or trauma. In cases of an early diagnosis and clinical presentation of sepsis, surgical treatment is favored. If it is diagnosed within the first 48 hours and there are no sepsis signs and minimal contamination, the endoscopic approach is preferred. ${ }^{3}$ Conservative management has rarely been reported in case series, but it could be proposed to patients with delayed diagnosis, no sepsis, and good tolerance of pleural contamination. Those in whom this approach fails are usually reconsidered for surgical management. ${ }^{4,5}$ However,

Received: March 11, 2017 Revised: June 23, 2017

Accepted: July 3, 2017

Correspondence: Juan Ignacio Tellechea

Department of Gastroenterology, North Hospital, University of Mediterranean, Chemin des Bourrely, Marseille 13915, France

Tel: +33-04-91-96-80-00, Fax: +33-04-91-96-80-01, E-mail: juanchoit@hotmail.com ORCID: https://orcid.org/0000-0002-1881-6441

(c) This is an Open Access article distributed under the terms of the Creative Commons Attribution Non-Commercial License (http://creativecommons.org/ licenses/by-nc/3.0) which permits unrestricted non-commercial use, distribution, and reproduction in any medium, provided the original work is properly cited. the development of endoscopic therapies (ET) may change the management of BS due to a mini-invasive approach and the use of different methods to close the defects without the risks of open surgery. Indeed, there are several case reports and publications in the literature regarding the endoscopic treatment of BS. This is our experience with the endoscopic management of BS.

\section{CASE REPORT}

\section{Patients and methods}

We included all adult patients ( $>18$ years) referred to our gastrointestinal and Endoscopy Unit who were diagnosed with a BS perforation between June 2004 and August 2015. Those patients who had another final diagnosis were excluded. All patients provided informed consent. This was a retrospective, observational, mono-centric, single-arm, consecutive case-series study that was not registered as a clinical trial and did not require institutional review board approval.

Included data: patient demographics, comorbidities, lesion characteristics, intended treatment (conservative, endoscopic, or surgical), need for additional treatments (if first attempt/ 
Table 1. Step-by-Step Details of the Surgical and Endoscopic Procedures including Technical Characteristics and Complications

\begin{tabular}{|c|c|c|c|}
\hline Case No. & Year & Conduct & Complication \\
\hline \multirow[t]{5}{*}{1} & 2004 & Drain $^{\text {a) }}+$ ES + Nissen fundoplication & Suture dehiscence \\
\hline & & AR-FCMS ${ }^{\text {b) }} 90 \times 22 \mathrm{~mm}$ & Stent migration \\
\hline & & AR-FCMS ${ }^{\mathrm{b})} 160 \times 22 \mathrm{~mm}$ & \\
\hline & & AR-FCMS ${ }^{\text {b) }} 90 \times 22 \mathrm{~mm}$ & \\
\hline & & Treatment success, discharge & Post-stent stenosis \\
\hline \multirow[t]{2}{*}{2} & 2008 & $\begin{array}{l}\text { Diagnostic } \\
\text { Drains }^{\text {a) }}+\text { ES }\end{array}$ & \\
\hline & & Treatment success, discharge & \\
\hline \multirow[t]{2}{*}{3} & 2010 & $\begin{array}{l}\text { Diagnostic } \\
\text { Conservative treatment }\end{array}$ & \\
\hline & & Treatment success, discharge & \\
\hline \multirow[t]{3}{*}{4} & 2010 & Drains $^{\text {a) }}$ & \\
\hline & & $\begin{array}{l}\text { Diagnostic } \\
\text { ES }\end{array}$ & \\
\hline & & Treatment success, discharge & \\
\hline \multirow[t]{5}{*}{5} & 2011 & Drain $^{\text {a) }}$ & \\
\hline & & $\mathrm{CMS}^{\mathrm{c})} 120 \times 18 \mathrm{~mm}$ & Stent migration \\
\hline & & FCMS $^{\text {d) }} 120 \times 24 \mathrm{~mm}$ & Stent migration \\
\hline & & $\mathrm{FCMS}^{\mathrm{e})} 120 \times 20 \mathrm{~mm}$ & \\
\hline & & Treatment success, discharge & \\
\hline \multirow[t]{2}{*}{6} & 2011 & $\begin{array}{l}\text { Diagnostic } \\
\text { Drain }^{\text {a) }}+E S\end{array}$ & \\
\hline & & Treatment success, discharge & \\
\hline \multirow[t]{2}{*}{7} & 2011 & $\begin{array}{l}\text { Diagnostic } \\
\text { Drain }^{\text {a) }}+\text { ES }\end{array}$ & \\
\hline & & Treatment success, discharge & \\
\hline 8 & 2012 & $\begin{array}{l}\text { Diagnostic } \\
\text { Drain }^{\text {a) }}+\text { Lewy Santy }\end{array}$ & Died first $24 \mathrm{hr}$ post treatment \\
\hline \multirow[t]{3}{*}{9} & 2013 & Drain $^{\text {a) }}$ & \\
\hline & & $\begin{array}{l}\text { Diagnostic } \\
\text { Drain }^{\text {a) }}+\text { ES }\end{array}$ & \\
\hline & & Treatment success, discharge & Pneumonia, eventration \\
\hline 10 & 2013 & Drain $^{\text {a) }}+$ LM, LP + OTSC $^{f)}+$ FCMS $\left.^{g}\right) 120 \times 20$ mm fixed w/2 clips ${ }^{\text {h) }}$ & Died first $24 \mathrm{hr}$ post treatment \\
\hline \multirow[t]{4}{*}{11} & 2014 & Drain $^{\text {a) }}+$ Nissen fundoplication & Suture leakage \\
\hline & & ES + Fundoplication reinforcement & \\
\hline & & $\mathrm{FCMS}^{\mathrm{e})} 150 \times 20 \mathrm{~mm}$ & \\
\hline & & Treatment success, discharge & \\
\hline \multirow[t]{3}{*}{12} & 2014 & $\operatorname{Drain}^{\text {i) }}+\mathrm{FCMS}^{\mathrm{e})} 150 \times 20 \mathrm{~mm}$ fixed w/2 clips ${ }^{\mathrm{h})}$ & Stent migration \\
\hline & & FCMS re-fixed w/3 clips ${ }^{\mathrm{h})}$ & \\
\hline & & Treatment success, discharge & Post-stent stenosis \\
\hline \multirow[t]{4}{*}{13} & 2015 & $\mathrm{LP}+$ local ATB $+\mathrm{OTSC}^{\mathrm{f})}+$ esophageal tube w/continue aspiration & Suture dehiscense \\
\hline & & $\mathrm{LP}+$ local ATB + FCMS ${ }^{\mathrm{e})} 150 \times 20 \mathrm{~mm}$ & \\
\hline & & $\mathrm{LP}+$ naso-cystic internal drain & \\
\hline & & $\mathrm{LP}+$ local ATB + FCMS ${ }^{\text {e) }} 150 \times 20 \mathrm{~mm}$ & \\
\hline
\end{tabular}


Table 1. Continued

\begin{tabular}{|c|c|c|c|}
\hline Case No. & Year & Conduct & Complication \\
\hline & & $\mathrm{LP}+$ naso-cystic internal drain & \\
\hline & & Drain in place + double pig tail plastic stent ${ }^{\mathrm{h})} 7 \mathrm{Fr} 10 \mathrm{~cm}$ & Cysto-bronchial fistula \\
\hline & & Drain in place $+\mathrm{FCMS}^{\mathrm{e})} 150 \times 20 \mathrm{~mm}$ & \\
\hline & & Metallic stent removal + naso-cystic drain in place + oral refeeding, discharge & \\
\hline \multirow[t]{7}{*}{14} & 2015 & Drain $^{\text {a) }}$ & \\
\hline & & ES & Suture leakage \\
\hline & & Drain $^{\text {a) }}+\mathrm{LP}+$ local ATB +OTSC ${ }^{\mathrm{f})}$ & Insufficient closure \\
\hline & & LP + FCMS ${ }^{\text {e) }} 120 \times$ AR-FCMS $20 \mathrm{~mm}$ fixed x/2 clips ${ }^{\text {h) }}$ & \\
\hline & & Discharge & \\
\hline & & Endoscopic control: in place and permeable stent & \\
\hline & & Metallic stent removal + control: fistula closure & \\
\hline
\end{tabular}

Nasogastric tube for esophageal aspiration.

ES, oversewing/primary suture; AR-FCMS, anti-reflux fully covered metallic stent; CMS, covered metallic stent; LM, endoscopic mediastinal cavity lavage; LP, endoscopic pleural cavity lavage; OTSC, over-the-scope-clips; ATB, amikacin (local), augmentin (amoxicillin+clavulanic acid, IV).

${ }^{a)}$ Previous surgical external drain.

${ }^{b}$ Hanarostent; Life Partners Europe, Bagnolet, France.

${ }^{c}$ Ultraflex NG covered; Boston Scientific, Marlborough, MA, USA.

${ }^{d)}$ Niti S enteral colonic; TaeWoong Medical, Seoul, Korea.

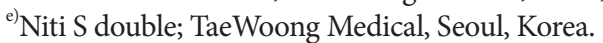

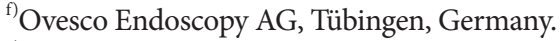

${ }^{g}$ Niti S; TaeWoong Medical, Seoul, Korea.

h) Cook, Bloomington, IN, USA.

${ }^{i)}$ Previous computed tomography-guided percutaneous drain.

approach fails), length of treatment, success rates, survival rates, and long-term follow-up.

The modalities used for patients who underwent ET included 12/6 t over-the-scope-clips (OTSC); esophageal self-expandable metallic stents (SEMS); through-the-scope clips; and local therapies consisting of through-the-scope lavage of mediastinal and/or pleural cavities, local antibiotics, and a novel therapy, internal drains (materials listed in Table 1). Endoscopies were performed by the interventional endoscopic team. A therapeutic videogastroscope with a large $3.8-\mathrm{mm}$ working channel (PENTAX Medical, Tokyo, Japan) was used. The therapeutic approach was determined using the endoscopist criteria in a case-by-case manner.

All patients were transferred to the intensive care unit with antibiotics, proton pump inhibitors, and enteral or parenteral nutrition support. The follow-up was performed by the Thoracic Surgery or Gastroenterology Departments.

\section{Results}

A total of 14 patients with BS were included (Table 2). All patients underwent upper-gastrointestinal endoscopy to confirm the diagnosis or for ET.

Only one patient received neither ET nor surgery and was managed conservatively (antibiotics, fasting, and fluid compensation) with a good outcome. Another patient was treated with computed tomography (CT) - guided percutaneous drainage of a collection seen on a CT scan as the first approach, secondarily completed by ET (metallic stenting). Surgery was the primary treatment modality in 10 patients, while ET was the primary intervention in two patients. ET was offered as primary treatment from 2010 onward; starting in 2015, patients also benefited from local ET. Thirteen of 14 patients required an internal, external, radiologically guided, or surgical drain.

All of the patients underwent an endoscopic procedure. Seven were exclusive diagnostic procedures; of them, four were performed at the initial management in the operating room and followed by surgery because of size or lesion localization. The other seven had ET. Only two underwent ET as first-line therapy: one had a successful treatment after Ovesco clipping with stenting followed by local ET and internal drains; the other was too unstable for surgery so an endoscopic approach was used, but this patient died of sepsis assertion and multi-organ failure within the first 24 hours.

Ten patients underwent a primary surgical therapy, four underwent external drain (ED) (pleural and/or mediasti- 
Table 2. Population, Clinical Onset, Diagnosis, and Endoscopic Findings

\begin{tabular}{ll}
\hline Gender & $4 \mathrm{~F} / 10 \mathrm{M}$ \\
\hline Mean age & $65,21 \mathrm{yr}$ (range, $41-82 \mathrm{yr}$ ) \\
\hline Procedence & $57.14 \%$ transferred from another hospital \\
\hline Admission & $92.85 \%$ at the urgency unit \\
\hline Primary symptom & $9 / 14$ vomiting and chest or abdominal pain \\
\hline Diagnosis method & $11 / 14$ patients $(78 \%)$ was achieved with CT scan \\
\hline Debut symptoms to & $7 / 14(50 \%)<24 \mathrm{hr}$ \\
\hline Endoscopy & $3 / 14$ between 24 hr, 4 days \\
\hline Endoscopic findings & $4 / 14$ longer time to endoscopy: $6,16,40,60$ days (due to prior surgery or a delayed derivation) \\
\hline Lesion localisation & $11 / 14$ lower esophagus \\
\hline Median lesion size $^{\circ}$ Insuflator & Lower esophagus: $6 / 11$ left side, $4 / 11$ anterior, $1 / 11$ posterior \\
\hline
\end{tabular}

CT, computed tomography; $\mathrm{CO}_{2}$, carbon dioxide.

nal) placement, three underwent esophageal repair of the perforation with esophageal suturing and ED placement, two underwent esophageal repair of the perforation with a suture in addition to Nissen fundoplication (not the most popular approach) with ED placement, while only one underwent esophagectomy with cardias resection for treatment of a very large perforation. Among them, three had primary efficacy (ED and primary repair with esophageal suturing), while one died after surgery (esophagectomy). The other six patients from the surgical treated group required second line treatment. Four of six needed a second surgical procedure; of these four, three had an esophageal repair of the perforation with suture. Of these three patients, two healed and the other required ET. The remaining patient required (after Nissen fundoplication) an esophageal repair with suture reinforcement of the fundoplication, although he ultimately required supplemental ET.

Five patients ultimately required ET as a "salvage" treatment. Two patients benefited from SEMS after a primary surgical treatment, while another benefited from SEMS after CT-guided percutaneous drain placement. Two patients required last-line salvage therapy after the failure of more than one surgical intervention: one who underwent previous $\mathrm{ED}$ placement + oversewing/primary suture benefited from an Ovesco clip + local ET + SEMS; the other benefited from SEMS after two fundoplications. The clinical progress of these patients is shown in Fig. 1 and Table 1.

In summary, the overall clinical success of the exclusive surgical management of BS was achieved in $50 \%$ of the patients (Table 3). Treatment failed in the other half of the patients; one died, as mentioned above, so $40 \%$ required ET. The overall clinical success of ET, meaning total wall healing, was $85 \%$. One patient died within the 24 hours after the first intervention (Table 3).

Only one patient required a single ET procedure. All patients required SEMS: a total of 13 stents were deployed, and the migration rate was $31 \%$. Three patients underwent OTSC placement associated with SEMS (Table 1).

Finally, after ET, none of the patients required an additional surgery. All of the patients were discharged with oral intake and without ED except for the patient with the internal naso-collection drain that was managed as outpatient ambulatory care until complete resolution of the para-esophageal/ mediastinal collection was achieved.

Four patients had complications. One patient experienced a cysto-bronchial fistula during ET that was successfully treated with the endoscopic placement of cystic internal drains (double pig tail plastic stents). Two patients had esophageal stenosis post-stenting that was successfully treated with endoscopic dilatation. One surgically treated patient presented with pneumonia in the follow-up period and underwent antibiotic treatment and surgical repair of the abdominal wall defect (Table 1).

\section{DISCUSSION}

The current management of BS includes conservative, endoscopic, and surgical treatments. The survival rates for each treatment are $75 \%, 100 \%$, and $81 \%$, respectively. The estimat- 


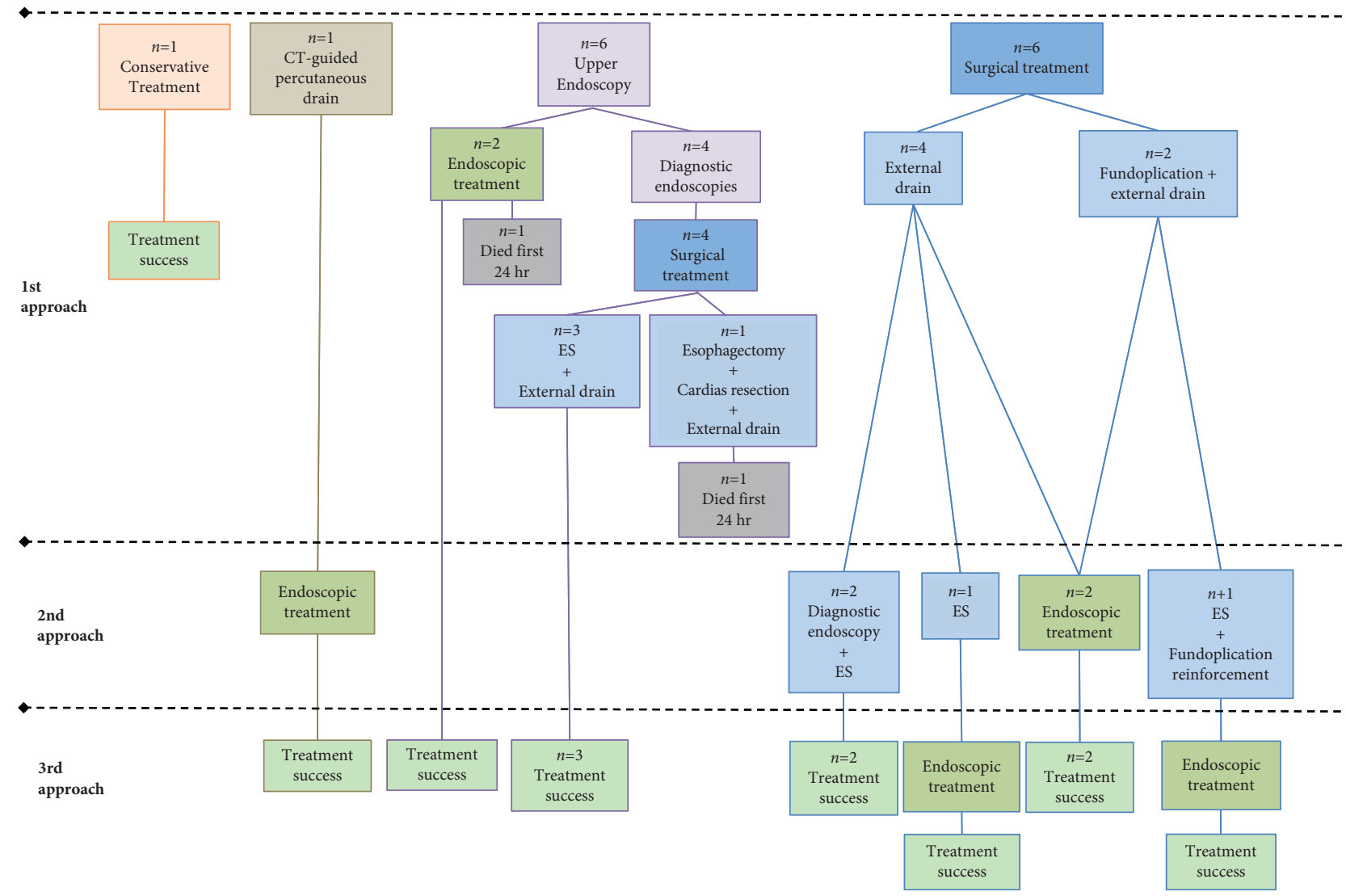

Fig. 1. Global management strategies, progression, and outcomes. CT, computed tomography; ES, oversewing/primary suture.

Table 3. Treatment Outcomes: Clinical Success Rates, Treatment Time, Number Procedures, Follow up, Number of Complications

\begin{tabular}{lcc}
\hline & Surgical therapy & Endoscopic therapy \\
\hline Clinical success (\%) & 50 & 85 \\
Median time of treatment: mo (range) & $1(1-2)$ & $3(1-8)$ \\
Median number of procedures to achieve success & $1,4(1-2)$ & $3(1-8)$ \\
Median time of follow up: mo (range) & $6(2-12)$ & $6(2-12)$ \\
Number of deaths & 1 & 1 \\
Complications (numbers) & 1 & 3 \\
\hline
\end{tabular}

ed global mortality rate of patients with BS is $20 \%-40 \% .^{3}$

Endoscopy is a proven effective tool in the diagnosis of BS, particularly in cases in which the diagnosis is suspected but findings on CT or a swallow study are inconclusive, because endoscopy enables specific lesion characterization. Our endoscopic descriptions were consistent with those in the literature, as lesion size $2.2 \mathrm{~cm}$ long and localized in the left lateral position of the lower esophagus in $90 \%$ of cases (Table 2$)^{3}$

Regarding endoscopic treatment, different therapeutic mechanisms can be proposed: derivation with self-expandable stents; closing with OTSC or other clipping devices; and local therapies consisting of through-the-scope lavage, local antibiotics, and naso-collection or double pig-tail internal drains. SEMS have been widely evaluated for use in cases of esophageal fistulas/leakage ${ }^{6}$ including patients with BS. In fact, the use of esophageal stents in association with chest tube drainage helped avoid surgery in $60 \%$ of patients in the first published series ${ }^{7}$ and displayed $100 \%$ clinical success in a recent study. ${ }^{8}$ Adverse events, consisting of an overall migration rate of $31 \%$, seems to be lower in our series $14 \%$ migration risk with fully covered double-type metallic stents $(1 / 7)$, as previously described by our team. ${ }^{6}$ Nevertheless, stent migration did not modify the clinical outcomes of our series because total wall healing was achieved in the majority 
of cases.

Regarding direct closure, seven cases requiring use of OTSC to treat BS were reported in the literature. ${ }^{9,10}$ The majority of cases required drain placement for the treatment of a contaminated cavity, and all were clinical successes. Five other cases were successfully treated with combination therapy consisting of OTSC or through-the-scope clips with a complementary metallic stent. ${ }^{10,11}$ Another study ${ }^{10}$ described the use of the Apollo Overstitch device alone, or with OTSC or through-the-scope clips in combination with SEMS in lesions yielded incomplete closure, in smaller lesion presentation than those in our series (median size of $1 \mathrm{~cm}$ ). Accordingly, OTSC might be more useful for perforations located in the esophagogastric junction that are $<20 \mathrm{~mm}$. Nevertheless, our patients had 20-, 20-, and 40-mm lesions and required additional ET, stenting, local therapies, and additional internal drains, probably due to large perforations or unfavorable localization.

In our series, one patient underwent combined therapy consisting of OTSC and SEMS for dehiscent closure. Thereafter, he benefited from ET (through-the-scope lavage) and was additionally treated with a novel technique: an internal naso-collection drain into a mediastinal collection including suction rinsing lavage and local antibiotics. After 8 months and eight endoscopic procedures, he completely recovered. Consequently, for pure esophageal perforations, the combination of OTSC with fully covered SEMS seems to have increased efficacy.

Although this was a heterogeneous population due to the retrospective nature of the study, we can conclude that the endoscopic treatment of BS is effective given the relatively low mortality rate in our series. This study displays our experience with this rare but very severe pathology, underlying the place of endoscopy as a diagnostic tool; treatment option when previous surgery attempts fail; primary treatment choice in selected patients with no septic signs or minimal cavity contamination in combination with drains; or treatment for patients who are not surgical candidates. The devices and techniques described could be combined to better resolve this problem. Ideally, a prospective study could help support and strengthen the recommendations displayed on this series and in the literature as well as define the indications, timing, anatomical characteristics, and sizes for which each treatment should be used.

\section{Conflicts of Interest}

The authors have no financial conflicts of interest.

\section{REFERENCES}

1. Anwuzia-Iwegbu C, Al Omran Y, Heaford A. Against all odds. Conservative management of Boerhaave's syndrome. BMJ Case Rep 2014;2014.

2. Derbes VJ, Mitchell RE Jr. Hermann Boerhaave's atrocis, nec descripti prius, morbi historia, the first translation of the classic case report of rupture of the esophagus, with annotations. Bull Med Libr Assoc 1955;43:217-240.

3. de Schipper JP, Pull ter Gunne AF, Oostvogel HJ, van Laarhoven CJ. Spontaneous rupture of the oesophagus: Boerhaave's syndrome in 2008. Literature review and treatment algorithm. Dig Surg 2009;26:1-6.

4. Darrien JH, Kasem H. Minimally invasive endoscopic therapy for the management of Boerhaave's syndrome. Ann R Coll Surg Engl 2013;95:552-556.

5. Griffin SM, Lamb PJ, Shenfine J, Richardson DL, Karat D, Hayes N. Spontaneous rupture of the oesophagus. Br J Surg 2008;95:1115-1120.

6. Gonzalez JM, Garces Duran R, Vanbiervliet G, et al. Double-type metallic stents efficacy for the management of post-operative fistulas, leakages, and perforations of the upper gastrointestinal tract. Surg Endosc 2015;29:2013-2018.

7. Fischer A, Thomusch O, Benz S, von Dobschuetz E, Baier P, Hopt UT. Nonoperative treatment of 15 benign esophageal perforations with self-expandable covered metal stents. Ann Thorac Surg 2006;81:467472.

8. van Heel NC, Haringsma J, Spaander MC, Bruno MJ, Kuipers EJ. Shortterm esophageal stenting in the management of benign perforations. Am J Gastroenterol 2010;105:1515-1520.

9. Musala C, Eisendrath P, Brasseur A, et al. Successful treatment of Boerhaave syndrome with an over-the-scope clip. Endoscopy 2015;47(Suppl 1) UCTN:E24-E25.

10. Dickinson KJ, Buttar N, Wong Kee Song LM, et al. Utility of endoscopic therapy in the management of Boerhaave syndrome. Endosc Int Open 2016;4:E1146-E1150.

11. González-Haba M, Ferguson MK, Gelrud A. Spontaneous esophageal perforation (Boerhaave syndrome) successfully treated with an overthe-scope clip and fully covered metal stent. Gastrointest Endosc 2016;83:650. 